\title{
SISTEM INFORMASI PENJUALAN ONLINE BERBASIS WEB UNTUK KEMUDAHAN PENJUALAN BARANG DI KOTA TERNATE
}

\author{
Harmianto ${ }^{1}$, Achmad Fuad ${ }^{2}$, Amal Khairan ${ }^{3}$ \\ Program Studi Teknik Informatika, Fakultas Teknik, Universitas Khairun \\ Jl.Jati Metro, Kota Ternate Selatan \\ E-mail :bobsatto5@gmail.com¹,ad_4ss@yahoo.com², ibntawakkal@gmail.com ${ }^{3}$
}

\begin{abstract}
Online sales have been widely applied in Indonesia, while in Ternate has not been able to use the Cash On Delivery (COD) facility provided by the existing trading system. In Ternate has used online trading but still uses group facilities on one of the social media, meanwhile the security is still lacking because the processing of member data is not verified properly. Therefore, an online sales information system was created around Ternate and applied a safer verification model in the trading process. The system development method used is the Waterfall method. In addition, the information system is very strict on member validation and payment, member validation is done while registration, the admin will block the member registration which is not the Ternateniese, North Maluku. On the payment process, the money or the price of the item purchased by the buyer is not immediately enter the seller's account but enter the Natezonedot.com account. Meanwhile, testing the system using black box, as for the things tested is the login and registration view. From the test results show that the system has been running as well as the function. In the implementation phase, it has been well-made, so it can be operated and used optimally particularly to the needs.
\end{abstract}

Keywords: Online Shop, Web, Waterfall, Apache.

Abstrak -- Penjualan online telah banyak diterapkan di Indonesia, namun di Kota Ternate belum dapat menikmati fasilitas Cash On Delivery (COD) yang disediakan oleh sistem jual beli yang ada. Di Kota Ternate sudah menikmati jual beli secara online namun masih menggunakan fasilitas grup disalah satu media sosial yang dimana dari sisi keamanannya masih terbilang kurang karena pengolahan data member tidak terverifikasi dengan baik. Maka dibuatlah sistem informasi penjualan online sekitar Kota Ternate dan menerapkan model verifikasi yang lebih aman pada proses jual beli. Metode pengembangan sistem yang digunakan adalah metode Waterfall. Sistem Informasi yang dibuat ini sangat ketat pada validasi member dan pembayaran, validasi member dilakukan pada saat registrasi, dimana yang bukan merupakan masyarakat Ternate Maluku Utara maka admin akan memblokir registrasi member tersebut, pada proses pembayaran, dimana uang atau harga barang yang dibeli oleh pembeli tidak langsung masuk ke rekening penjual melainkan masuk ke rekening Natezonedot.com. Pengujian sistem menggunakan black box adapun hal yang diuji adalah tampilan login dan registrasi. Dari hasil pengujian menunjukan bahwa sistem yang dibangun sudah berjalan sesuai dengan fungsi yang diberikan. Dalam tahap implementasinya telah dibuat dengan baik sehingga dapat dioperasikan dan digunakan secara optimal dan sesuai dengan kebutuhan.

Kata kunci : Penjualan Online, Web, Waterfall, Apache

\section{PENDAHULUAN}

Penjualan online adalah melakukan aktifitzzas penjualan dari mencari calon pembeli sampai menawarkan produk atau barang dengan memanfaatkan jaringan internet yang didukung dengan seperangkat alat elektronik sebagai penghubung dengan jaringan internet.

Masyarakat di Kota Ternate juga sudah menikmati dan dapat melakukan penjualan maupun pembelian secara online.Walaupun sistem penjualan online makin banyak, namun di sekitar Kota Ternate belum bisa menerapkan model pembayaran Cash On Delivery (COD) dikarenakan lokasi penjualnya berada jauh dari Kota Ternate (berbeda pulau/daratan). Sehingga yang jadi persoalan belum adanya sistem penjualan online lokal yang mampu menyediakan sarana prasarana alat lokal yang dapat dilakukan transaksi lokal seperti COD sehingga lebih aman.
Sebenarnya sistem penjualan online yang dapat memfasilitasi penjualan khusus di Kota Ternate sudah ada namun masih menggunakan fasilitas grup disalah satu media sosial yang dimana dari sisi keamanannya masih terbilang kurang, terbukti dengan adanya komplen dari beberapa pembeli yang dimana terjadi penipuan.

Maka itu dibuatlah sebuah Sistem Informasi Penjualan Online E-Commerce berbasis website, yang diharapkan dapat membantu masyarakat Kota Ternate untuk melakukan transaksi lebih aman dan penjual khusus di kota Ternate dapat lebih variatif menawarkan produk-produk lokal.

\section{TINJAUAN PUSTAKA}
A. Sistem Informasi
Suatu sistem merupakan suatu jaringan kerja dari prosedur-prosedur yang saling berhubungan, 
berkumpul bersama - sama untuk melakukan suatu kegiatan atau menyelesaikan suatu sasaran tertentu.

Informasi merupakan data yang telah diolah sedemikian rupa sehingga memiliki makna tertentu bagi penggunanya. Untuk memperoleh informasi, diperlukan adanya data yang akan diolah dan unit pengolah [3].

\section{B. E-Commerce}

E-commerce adalah "Bisnis yang dilakukan secara elektronik yang melibatkan aktivitas-aktivitas bisnis berupa business to business ataupunbusinessto consumen melalui teknologi internet." E-business adalah transaksi yang menggunakan media elektronik yang dipergunakan untuk berjualan atau proses pembelian atau proses pembelian suatu atau beberapa produk menggunakan teknologi ICT(Information and Communication Technology) [4].

\section{Web}

Word Wide Web (WWW) atau biasa disebut dengan web, merupakan salah satusumber daya internet yang berkembang pesat. Informasi web disebarluaskan melalui pendekatan hypertext (salah satu cara untuk menghubungkan berbagai dokumen di internet) yang memungkinkan suatu teks pendek menjadi acuan untuk membuka dokumen yang lain [2].

\section{Apache}

Apache adalah Web server yang merupakan inti dari sebuah web hosting, Sistem enkripsinya lebih rumit daripada $\mathrm{SSH}$

karena selain hal teknis yang lebih rumit juga melibatkan aspek non teknis seperti Certificate Authority (CA). Server side scripting atau CGI (Common Gateway Interface) yang biasa dipakai pada Apache adalah PHP (PHP Hypertext Prepocessor), versi terakhir yang stabil adalah 4.0.4pl1 dengan banyak kelebihan dibanding versi stabil sebelumnya [1].

\section{E. Waterfall}

Model waterfall adalah suatu model proses untuk memodelkan susatu sistem perangkat lunak yang dibuat secara terstruktur dan berurutan dimulai dari penentuan masalah Requirement, system and design software, implementation and unit testing, integration and system testing, dan maintenance bagan model waterfall dapat dilihat pada gambar 1. dibawah ini :

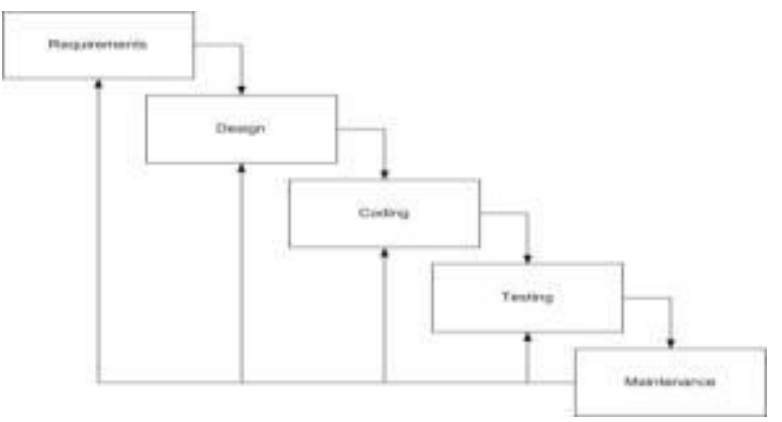

Gambar 1. Bagan Model waterfall [5].

\section{METEDOLOGI PENELITIAN}

A. Metode Pengembang Perangkat Lunak Langkah-langkahnya adalah sebagai berikut :

1. Analisa, pada tahap analisaakan menganalisis bagaimana sistem penjualan online ysng dilakukan oleh komunitas penjual dan pembeli di kota Ternate. Dari tahap analisa ini juga nantinya akan mengalir informasi informasi yang di butuhkan oleh user. Dari informasi inilah yang menjadi acuan sistem analisa untuk menerjemahkan kedalam bentuk bahasa pemograman.

2. Desain Sistem, pada tahapan ini penulis melakukan perancangan dari Sistem Informasi Penjualan Online yang akan di buat terhadap permasalahan yang ada, dengan menggunakan perangkat permodelan diagram alir (data flow diagram) yang nantinya akan alur dari Sistem Informasi Penjualan Online Berbasis Web untuk Kemudahan Penjualan Barang di Kota Ternate dan diagram hubungan entitas.

3. Kode program,penulisan Kode Program, tahap ini merupakan penerapan dari Desain Sistem yang direncanakan oleh peneliti, pada tahap ini yang akan menghasilkan sebuah program yang telah direncanakan

4. Pengujian, setelah tahap pengkodean dari aplikasi selesai maka akan dilakukan testing dari Sistem Informasi Penjualan Online ini untuk menemukan kesalahan-kesalahan dari aplikasi yang kemudian nantinya dilakukan pengkajian ulang dan perbaikan.

5. Pemeliharaan, Penerapan program dan pemeliharaan, pada tahap ini penulis akan menerapkan Sistem yang telah dibuat, dan penulis melakukan pemeliharaan pada saat aplikasi dijalankan jika ditemukan kesalahan - kesalahan yang tidak ditemukan sebelumnya.

\section{B. Sistem yang berjalan}

Berikut adalah sistem yang berjalan. Tabelnya dapat dilihat pada tabel 2 .

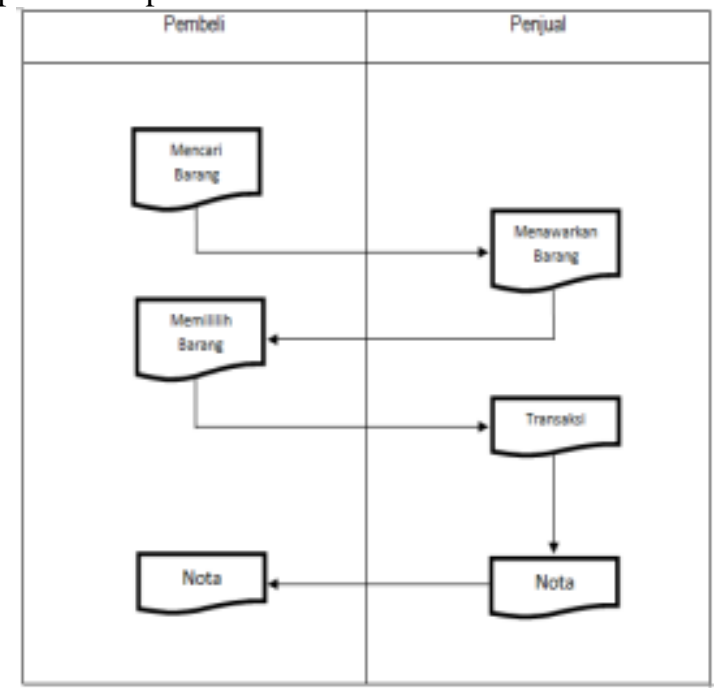

Tabel 2. Sistem yang berjalan 


\section{Perancangan ERD}

Perancangan database merupakan proses untuk menentukan isi dan pengaturan data yang dibutuhkan untuk mendukung berbagai rancangan sistem. Perancangan database menggunakan ERD (Entity Relationship Diagram).

Pada perancangan ERD (Entity Relationship Diagram), terdapat 7 Tabel yaitu tabel pembeli, tabel barang, tabel pemesanan, tabel penjual, tabel transaksi, tabel alamat dan tabel kirim. Perancangan ERD dari tabel-tabel tersebut dapat dilihat pada gambar 3.

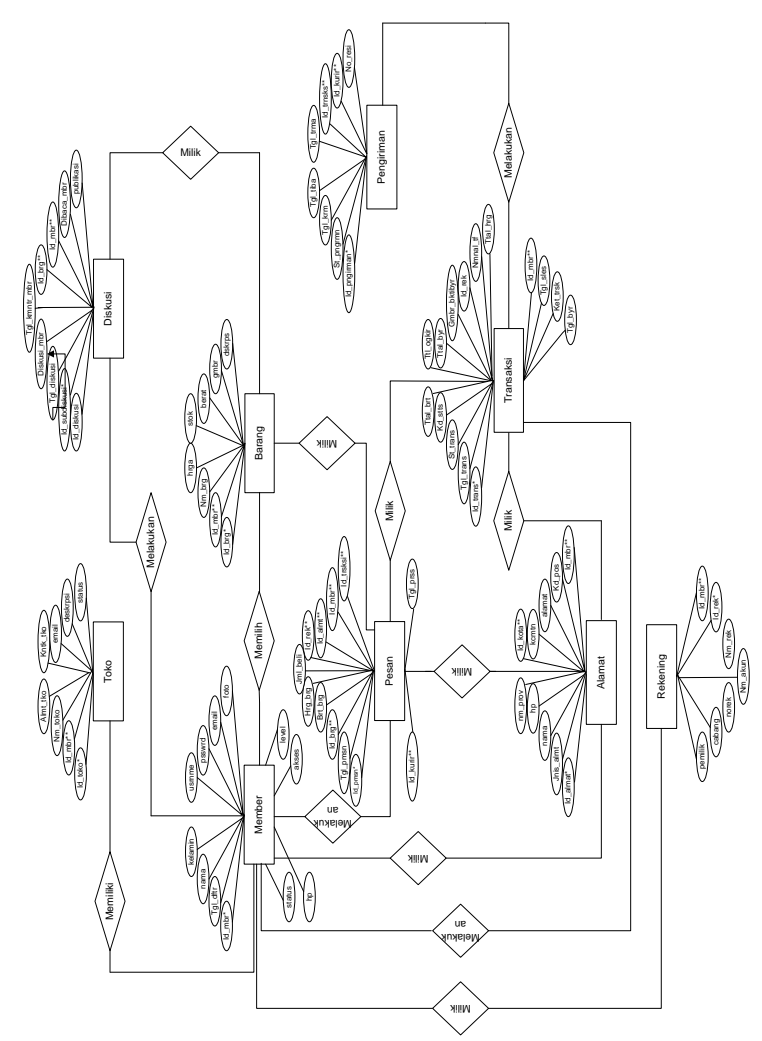

Gambar 3. Perancangan ERD

\section{HASIL DAN PEMBAHASAN}

\section{A. Tampilan Aplikasi}

Untuk memperjelas bentuk implementasi sistem aplikasi di atas, berikut tampilan-tampilan aplikasi yang telah dibuat.

1. Tampilan Formutama pengunjung

Tampilan halaman utama akan tampil pada saat pengunjung membuka halaman website Natezonedot.com in i. Pada halaman ini terdapat menu beranda, produk, registrasi, dan login.Menu beranda dan produk menampilkan produk jual, menu registrasi berfungsi untuk mendaftarkan diri sebagai member pada natezonedot.com, dan login digunakan untuk masuk jika sudah terdaftar sebagai member.Codingan pada tampilan ini dapat dilihat pada lampiran dan tampilannya dapat dilihat pada gambar 4 .

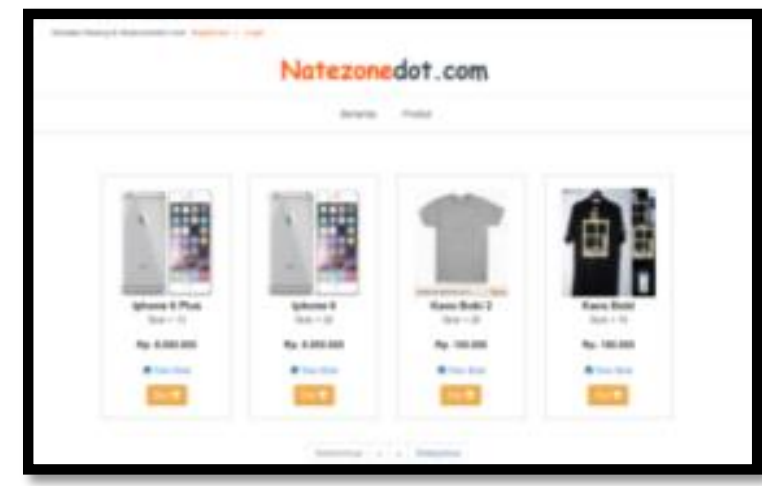

Gambar 4 Halaman Utama Pengunjung

2. Tampilan Halaman Login

Pada tampilan halaman login, terdapat field untuk masukkan username dan password. Jika username dan password yang dimasukkan dengan benar maka prosesnya berlanjut, tetapi jika salah maka akan tampil notifikasi kesalahan pada username dan password, jika username yang salah maka akan tampil notifikasi username salah, begitupun jika password yang salah makan akan tampil notifkasi password salah, dan jika username dan password yang salah maka akan muncul notifikasi username dan password salah akan kembali tampil ke halaman login. Codingan pada tampilan ini dapat dilihat pada lampiran dan tampilan login dapat dilihat pada gambar 5 .

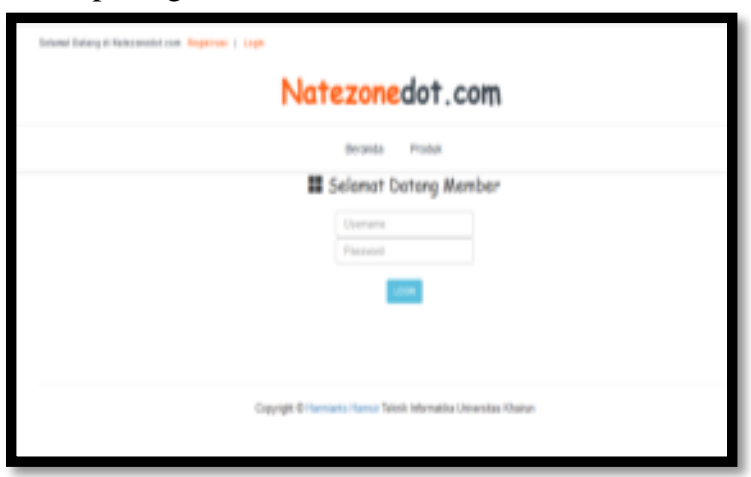

Gambar 5. Tampilan Halaman Login

\section{Tampilan Registrasi}

Pada tahap registrasi ini diterapkan sistem validasi yang sangat ketat dimana pada saat member melakukan registrai maka data yang dikirim ke sistem terlebih dahulu akan diperiksa oleh admin. Jika data yang dikirim tidak sesuai dengan ketentuan maka admin akan menolak atau tidak mengkonfirmasi registrasi tersebut. Validasi tersebut dinilai dari foto identitas diri yang dikirim oleh pendaftar dan akan dinilai dari alamat yang tertera pada kartu identitas, apabila pendaftar bukan merupakan penduduk di Kota Ternate atau Maluku Utara maka admin akan menolak. Hal ini dilakukan agar mempermudah pengolahan data dan penyaringan member sehingga member yang terdaftar merupakan penduduk asli Kota Ternate atau Maluku Utara. 


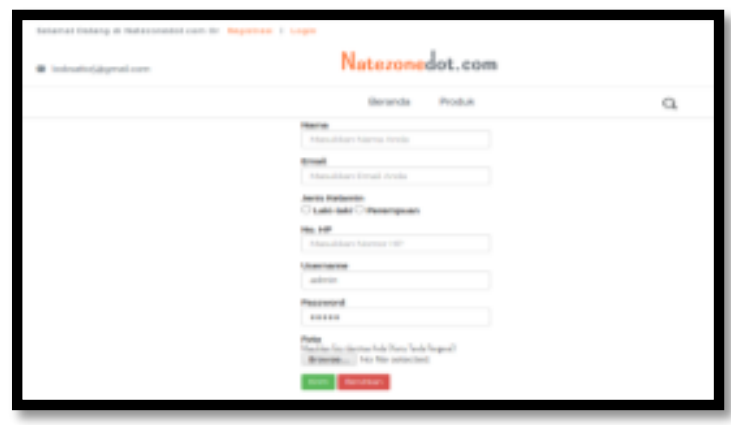

Gambar 6. Tampilan halaman registrasi

4. Tampilan halaman produk

Menu produk menampilkan semua produk yang ada pada Natezonedot.com serta proses pembelian hingga proses pembayaran. Prosesnya mulainya dari membuka halaman produk, detail produk dapat dibuka dengan mengklik gambar produk, proses beli dan masuk ke keranjang belanja kemudian melakukan checkout hingga lanjut ke pembayaran dan mengupload bukti pembayaran.Tampilannya dapat dilihat pada gambar 7 .

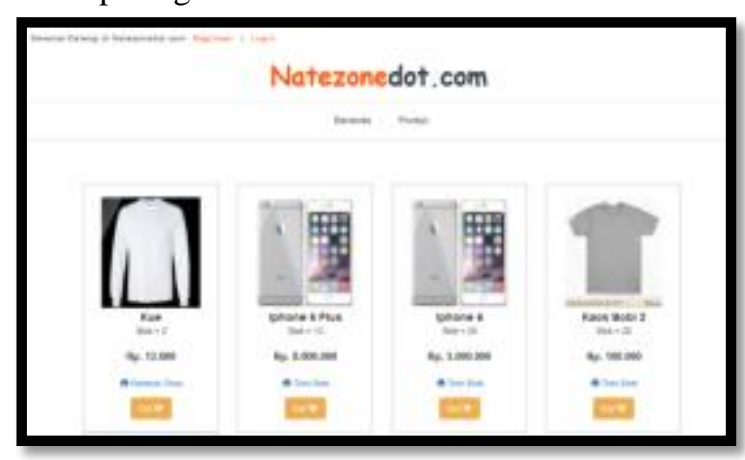

Gambar 7. Tampilan Halaman Produk

Tampilan form beli merupakan tampilan yang akan muncul apabila pembeli mengklik tombol beli pada produk. Codingan pada tampilan ini dapat dilihat pada lampiran dan tampilannya dapat dilihat pada gambar 8.

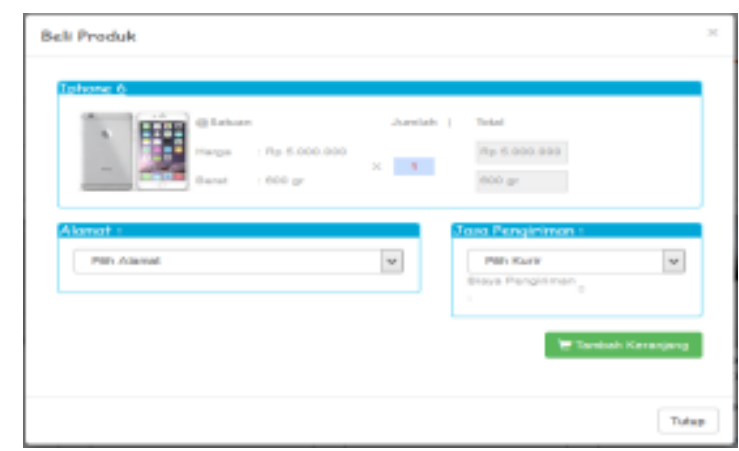

Gambar 8. Tampilan Form Beli

Tampilan keranjang merupakan penampungan barang yang akan dibeli sebelum melakukan checkout. Codingan pada tampilan ini dapat dilihat pada lampiran dan tampilannya dapat dilihat pada gambar 9.

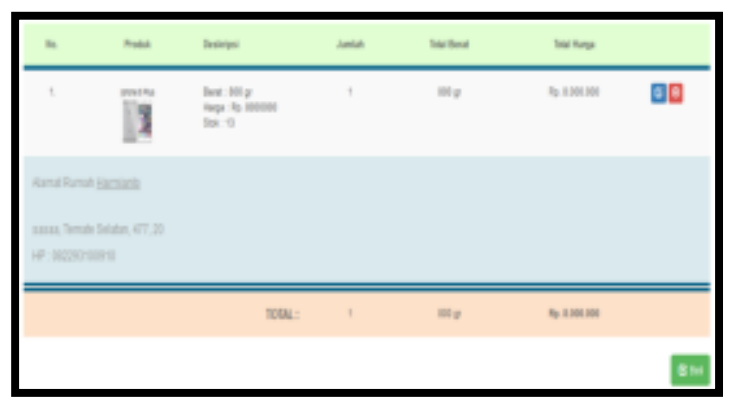

Gambar 9. Tampilan Keranjang

Halaman checkout merupakan halaman step kedua setelah keranjang sebelum melakukan pembayaran. Sebelum melakukan pembayaran, pembeli wajib mengisi data bank.Codingan pada tampilan ini dapat dilihat pada lampiran dan tampilannya dapat dilihat pada gambar 10 .

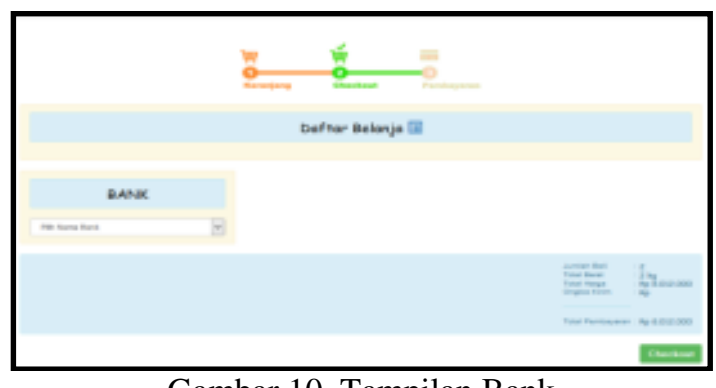

Gambar 10. Tampilan Bank

5. Halaman Registrasi Toko

Tampilan registrasi toko digunakan oleh penjual untuk membuka toko agar dapat melakukan penjualan di natezonedot.com, tanpa membuka toko maka penjual tidak dapat melakukan penjualan. Data yang diisi meliputi nama toko, alamat toko, kontak toko, email toko, dan deskripsi tentang toko. Apabila toko telah aktif, penjual tidak hanya dapat melakukan penjualan namun dapat melihat barang yang dijual oleh toko tersebut. Tampilannya dapat dilihat pada gambar 11.

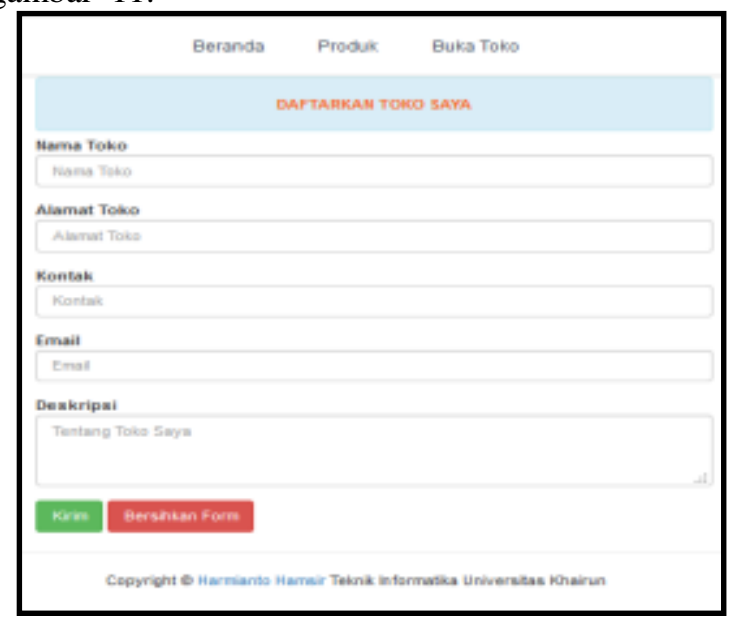

Gambar 11. Tampilan Registrasi Toko

6. Tampilan tambah data barang.

Pada tampilan tambah barang digunakan oleh penjual untuk menginput data barang yang akan dijual di Natezonedot.com. Data yang diinput meliputi nama 
barang, harga, stok, berat, deskripsi, dan gambar barang. Tampilannya dapat dilihat pada gambar 12 .

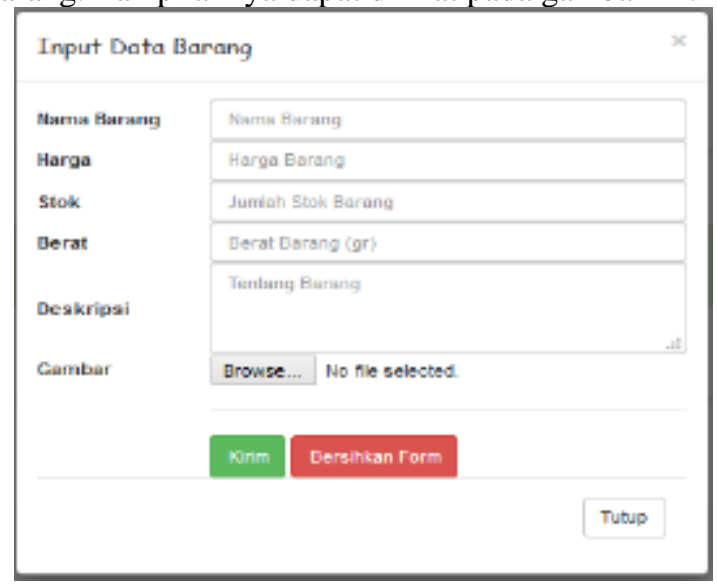

Gambar 12. Tampilan Tambah Barang.

B. Pengujian aplikasi

Pengujian sistem yang digunakan untuk menguji yang baru adalah metode pengujian Black Box. Pengujian Black Box berfokus pada persyaratan fungsional perangkat lunak, dimana Black Box lebih mengutamakan input dan outputnya. Untuk pengujian sistem data benar dan data salah dapat dilihat selengkapnya pada tabel 1 sampai 16 dan gambar 4.10 sampai 4.20 .

Tabel 1. Tabel Login Benar

\begin{tabular}{|c|c|c|c|}
\hline \multicolumn{4}{|c|}{ Hasl uี| dog salah| } \\
\hline Data masukan & Invotan & Penganatan & Kesinpilen \\
\hline $\begin{array}{l}\text { Llsamane : salah } \\
\text { Passuodi benar }\end{array}$ & Usentane terisi davan salah & Usamane tidak vaid & Dodeds \\
\hline
\end{tabular}

Tampilan login berhasil dilihat pada gambar 13 .

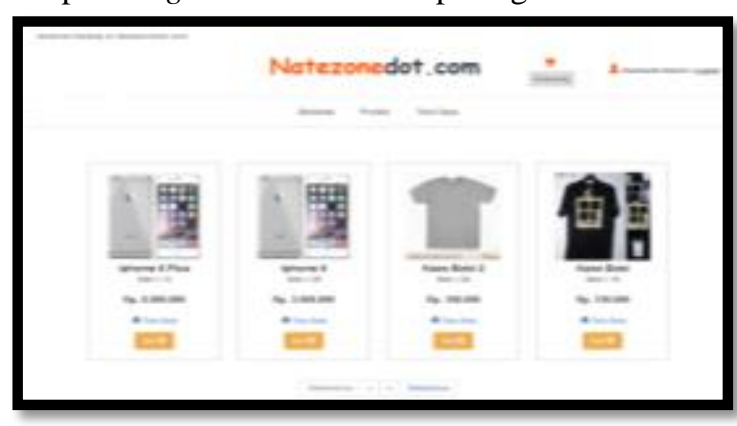

Gambar 13. Tampilan Login Berhasil

. Tabel 2. Tabel Username Salah

\begin{tabular}{|c|c|c|c|}
\hline \multicolumn{4}{|c|}{ Hasil uij| deta salah) } \\
\hline Deth mesulken & Inqutan & Pengarratan & Kesimpulan \\
\hline $\begin{array}{l}\text { Usemante saleh } \\
\text { Passsurd: bentar }\end{array}$ & Ustmametenisidengan satch. & Usemame fiak vald & Dttak \\
\hline
\end{tabular}

Tampilan input username salah dapat dilihat pada gambar 14.

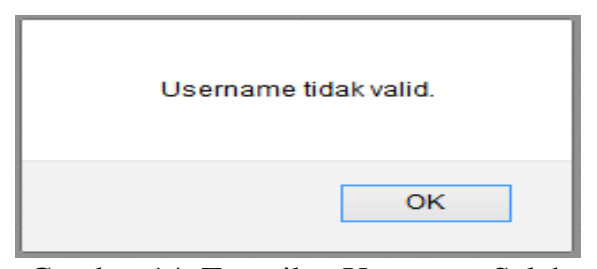

Gambar 14. Tampilan Username Salah

Tabel 3. Tabel Password Salah

\begin{tabular}{|c|c|c|c|}
\hline \multicolumn{4}{|c|}{ Hasil a.ji|(data bena) } \\
\hline Dota nasskan & Inputan & Pengamotan & Keșimęulan \\
\hline Date Peghistusi & $\begin{array}{l}\text { Daia negistriai tenis dargan } \\
\text { bera. }\end{array}$ & Reajstasi bettosil & Dterima \\
\hline
\end{tabular}

Tampilan input data registrasi berhasil dapat dilihat pada gambar 15 .

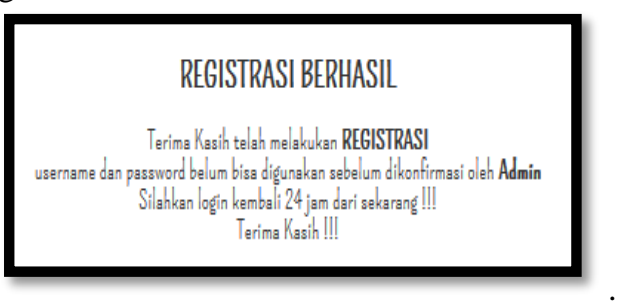

Gambar 15. Tampilan Registrasi Berhasil

Tabel 4. Tabel Registrasi Salah

\begin{tabular}{|c|c|c|c|}
\hline \multicolumn{4}{|c|}{ Hasil ui (dath berst) } \\
\hline Data masuken & mpulan & Pengamadan & Kesinpulan \\
\hline Data Regitras & $\begin{array}{l}\text { Dala nejistrasi leiri dengan } \\
\text { sath }\end{array}$ & Peagitias gagyal & Dotolak \\
\hline
\end{tabular}

Tampilan format penulisan nama salah dapat dilihat pada gambar 16.

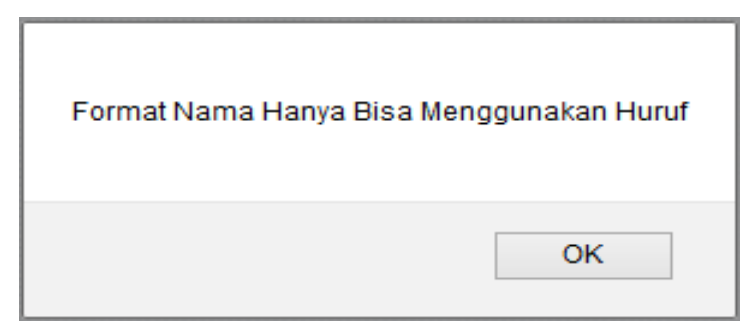

Gambar 16. Tampilan data benar dari halaman login

Tampilan email telah terdaftar dapat dilihat pada gambar 17.

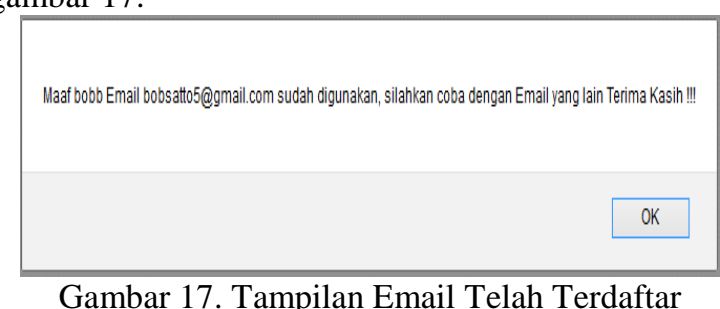

Tampilan username telah terdaftar dapat dilihat pada gambar 18 . 


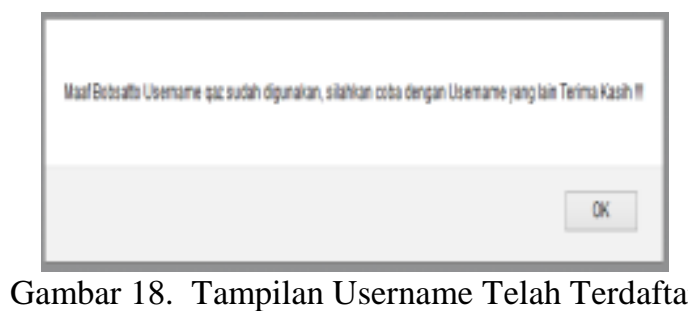

Tampilan format penulisan nomor HP salah dapat dilihat pada gambar 19 .

No HP Hanya Bisa Diisi Dengan Angka

Gambar 19. Tampilan Format Nomor HP Salah

Tabel 5. Tabel Input Data Barang Benar

\begin{tabular}{|c|c|c|c|}
\hline \multicolumn{4}{|c|}{ Hasil vii (data baras) } \\
\hline Data masula1 & Inputan & Pengamatan & Kesinpular \\
\hline Dzta Barang & $\begin{array}{l}\text { Data berreng terisi dengan } \\
\text { salah. }\end{array}$ & $\begin{array}{l}\text { Tanpl halanan inpur } \\
\text { data tratg }\end{array}$ & Otsak \\
\hline
\end{tabular}

Tampilan input data harga dengan menggunakan format selain angka dapat dilihat pada gambar 20 ..

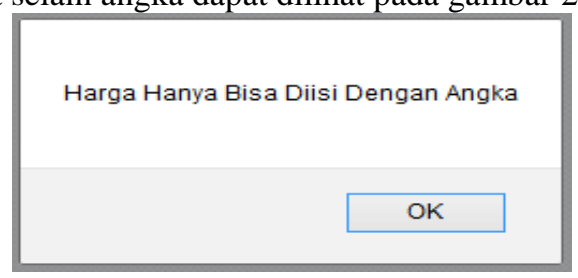

Gambar 20. Tampilan Input Harga Salah

Tampilan input data stok dengan menggunakan format selain angka dapat dilihat pada gambar 21 .

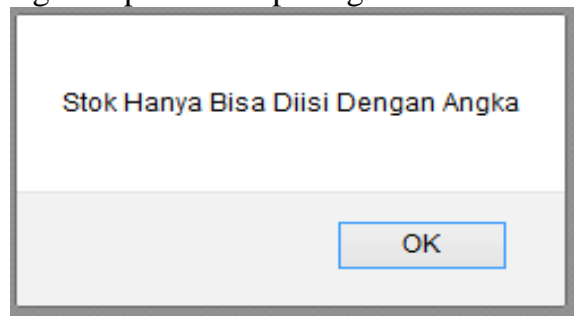

Gambar 21. Tampilan Input Stok Salah

Tampilan input data berat dengan menggunakan format selain angka dapat dilihat pada gambar 22 ..

Berat Hanya Bisa Diisi Dengan Angka

\section{OK}

Gambar 22. Tampilan Input Berat Salah
Tabel 6 Tabel Input Checkout Benar

\begin{tabular}{|c|c|c|c|}
\hline \multicolumn{4}{|c|}{ Hasi uip(data benra) } \\
\hline Data mas.ken & mpotalo & Pangamaten & Kesimpulan \\
\hline Data chediout & $\begin{array}{l}\text { Data bareng ferisi cengar } \\
\text { sald. }\end{array}$ & $\begin{array}{l}\text { Tampl halanan } \\
\text { chechouf }\end{array}$ & Dhold \\
\hline
\end{tabular}

Tampilan bank kosong pada halaman checkout dapat dilihat pada gambar 23 ..

Kesalahan...! Anda belum memilih Bank

Gambar 23. Bank Kosong

\section{KESIMPULAN DAN SARAN}

\section{Kesimpulan}

Dalam penelitian yang dilakukan dapat diambil kesimpulan yaitu:

1. Aplikasi sistem informasi penjualan online dibuat menggunakan phpMyAdmin, notepad ++ , dan microsoft visio 2010 dalam proses implementasi tersebut berjalan dengan baik, itu dibuktikan dengan adanya sistem yang berjalan dan juga telah diuji.

2. Pada sistem ini telah diterapkan model verifikasi yang lebih aman yaitu pada registrasi member dan pembayaran. Bentuk verifikasi member dilakukan pada saat registrasi toko, dimana yang bukan merupakan masyarakat Ternate atau Maluku Utara maka admin akan memblokir registrasi toko tersebut. Begitupun dengan proses pembayaran, dimana uang atau harga barang yang dibeli oleh pembeli tidak langsung masuk ke rekening penjual melainkan masuk ke rekening Natezonedot.com.

3. Dalam tahap implementasi telah dirancang dengan baik sehingga sistem yang telah dibuat dapat dioperasikan dan digunakan secara optimal dan sesuai dengan kebutuhan. Tahan perancangan dimulai dari pembuatan diagram berjenjang, diagram konteks, DFD, hingga perancangan database dan proses coding dilakukan dengan menggunakan bahasa pemrograman PHP dan database menggunakan MySQL.

4. Dalam pengujian blackbox telah menunjukkan bahwa sistem telah berjalan dengan baik, seperti yang terdapat pada pengujian tampilan login, registrasi, input data barang dan checkout. Apabila data yang diinput pada menu login bernilai benar makan prosesnya akan berlanjut ke menu utama sistem, dan apabila data yang diinput pada menu registrasi benar, maka akan diproses dan dikonfirmasi oleh admin dan kemudian terdaftar sebagai member, dan pada checkout apabila data telah terisi dengan benar maka akan berlanjut ke proses pembayaran. 
Namun apabila data yang dinput bernilai salah maka akan muncul informasi sesuai dengan kesalahan yang terjadi.

5. Sistem informasi penjualan online ini dapat memudahkan penjualan dan pembelian barang yang berasal dari Kota Ternate, dikarenakan pembeli tidak perlu berkeliling mencari barang dan penjualpun mempunyai wadah untuk menjual barangnya khususnya untuk di Kota Ternate tanpa perlu takut akan terjadi hal-hal negatif misalnya penipuan.

\section{Saran}

Agar dapat menggunakan aplikasi dengan baik, maka diberikan saran - saran sesuai penulis dalam menyelesaikan tugas akhir ini :

1. Perlu adanya pengembangan pada sistem informasi berbasis web ini untuk penelitan selanjutnya. Seperti dikembangkan ke dalam sistem yang berbasis android untuk lebih memudahkan pengguna menggunakan ke smartphone, karena pada saat ini masyarakat lebih banyak melakukan pembelian maupun penjualan dengan menggunakan aplikasi yang dapat digunakan pada smartphone.

2. Perlu ada pengembangan fitur yang belum terdapat pada sistem ini agar dapat menunjang kemajuan system, seperti fitur Chatting dan COD yang masih manual.

\section{DAFTAR PUSTAKA}

[1] Djoni, Alex. 2002. Aplikasi E-Commerce www.komputeronline.com dengan menggunakan MySQL dan PHP4.Universitas Kristen Petra. Surabaya.

[2] Ludiyanto, wawan. 2010. Notifikasi Layanan Pengiriman Email Masuk Berbasis SMS Gateway. Universitas Pembangunan Nasional "Veteran" Jawa Timur. Surabaya.

[3] Puspita Dwi Astuti. 2011. Sistem Informasi Penjualan Obat Pada Apotek Jati Farma Arjosari.

[4] Sri Haryanti, Tri Irianto. 2011. Rancang Bangun Sistem Informasi E-Commerce Untuk Usaha Fashion Studi Kasus Omah. Universitas Surakarta. Surakarta.

[5] Sumiyati. 2017. Sistem Informasi Inventory Berbasis Web dengan Konsep Group Technology pada Perum Bulog Sub Divre Wilayah Ternate. Universitas Khairun. 